\title{
Jurisprudência do Tribunal de São Paulo em ações de responsabilidade civil por erro médico em cirurgias do quadril
}

\author{
Rulings of the Court of Appeal of the State of São Paulo \\ in cases of hip surgery malpractice
}

\author{
Adriana Salvany Fabricio ${ }^{1}$, Sidney de Carvalho Fabricio², \\ Márcia Vieira da Motta ${ }^{3}$
}

DOI: http://dx.doi.org/10.11606/issn.2317-2770.v24i2p74-83

\begin{abstract}
Fabricio AS, Fabricio SC, Motta MV. Jurisprudência do Tribunal de São Paulo em ações de responsabilidade civil por erro médico em cirurgias do quadril. Saúde, Ética \& Justiça. 2019;24(2):74-83.

RESUMO: A incidência de ações por erro médico vem crescendo ao longo dos anos no Brasil, sendo, em sua maioria, relacionadas a procedimentos cirúrgicos. A área ortopédica, devido à grande quantidade de cirurgias realizadas em sua prática, encontra-se dentre as especialidades com risco considerável de processos indenizatórios. As cirurgias do quadril representam grande parte do volume de cirurgias ortopédicas. Este trabalho analisou o perfil das decisões judiciais em âmbito cível relacionadas a má prática profissional, em cirurgias na região do quadril, no Tribunal de Justiça do Estado de São Paulo - TJSP, no ano de 2018. Das 14 decisões encontradas em segunda instância, de ações de responsabilidade civil por erro médico em cirurgias no quadril, a maioria $(57,1 \%)$ foi considerada improcedente, não tendo sido caracterizada a culpa na conduta profissional. Dos cinco casos considerados procedentes, em quatro houve culpa na conduta do médico que realizou a cirurgia, sendo que em um caso houve responsabilização apenas pela conduta do hospital e não dos médicos, por tratar-se de infecção hospitalar. Em todos os casos em que houve condenação, a responsabilização do médico foi devida à inobservância de condutas padronizadas na literatura médica ou por uso de técnicas cirúrgicas não adequadas aos padrões descritos cientificamente.
\end{abstract}

DESCRITORES: Procedimentos Ortopédicos; Erros Médicos; Defesa do Consumidor; Imperícia; Imprudência; Má Conduta Profissional; Jurisprudência; Responsabilidade Legal; Responsabilidade Civil.

\footnotetext{
${ }^{1}$ Médica Radiologista do Setor de Ultrassonografia do Grupo Fleury. Pós-graduanda em Medicina Legal e Perícias Médicas pela Faculdade de Medicina da Universidade de São Paulo.

2. Médico Ortopedista no Hospital Geral de Itapecerica da Serra. Coordenador Médico do Pronto Atendimento Maria Dirce.

3.Professora do Curso de Especialização em Perícias Médicas da Faculdade de Medicina da Universidade de São Paulo. Departamento de Medicina Legal, Ética Médica e Medicina Social e do Trabalho.

Endereço para correspondência: marcia.motta@gmail.com
} 


\section{INTRODUÇÃO}

A ções de erro médico fazem parte do grande movimento da judicialização na área da saúde em que o judiciário atua como agente consolidador da política de saúde nacional, garantindo a efetivação dos direitos dos pacientes e dos profissionais que prestam serviço na área. Neste sentido, o Direito Civil pátrio estabeleceu parâmetros que regem a responsabilidade civil pelo dano causado ou por propiciar-se diminuição do bem jurídico da vítima, de tal modo que, no centro deste subsistema encontra-se o cometimento do ato ilícito civil, nos termos do enunciado normativo contido no art. 186 do Código Civil1 ${ }^{1}$ :

Art. 186. Aquele que, por ação ou omissão voluntária, negligência ou imprudência, violar direito e causar dano a outrem, ainda que exclusivamente moral, comete ato ilícito.

Como corolário do cometimento do ilícito civil, atribui-se ao agente a responsabilidade, nos moldes delineados pelo artigo 927 do mesmo Codex ${ }^{1}$ :

Art. 927. Aquele que, por ato ilícito (arts. 186 e 187), causar dano a outrem, fica obrigado a repará-lo.

Parágrafo Único. Haverá obrigação de reparar o dano, independentemente de culpa, nos casos especificados em lei, ou quando a atividade normalmente desenvolvida pelo autor do dano implicar, por sua natureza, risco para os direitos de outrem.

Atrelada à composição do ilícito civil ensejador da responsabilização, encontra-se o elemento subjetivo culpa, caracterizada pela conduta negligente, imprudente ou imperita do agente. É importante destacar que a responsabilidade do profissional no exercício de suas funções não se restringe ao dano per se, mas inclui o agravamento do mal que já acometia o paciente:

Art. 951. O disposto nos arts. 948, 949 e 950 aplica-se ainda no caso de indenização devida por aquele que, no exercício de atividade profissional, por negligência, imprudência ou imperícia, causar a morte do paciente, agravar-lhe o mal, causar-lhe lesão, ou inabilitá-lo para o trabalho.

Nas ações de responsabilidade civil, o médico responderá de acordo com a legislação aplicada ao âmbito do serviço que presta, se público ou privado, sendo o primeiro basicamente civilista e o segundo, consumerista. Médicos de hospitais privados que atuam como agentes públicos, por exemplo, em caso de transplantes pelo Sistema Único de Saúde (SUS), tem a responsabilidade civil de suas condutas pautadas pela Constituição Federal $^{2}$ e pelo Código Civil1:

\section{Constituição Federal}

Art. 37. A administração pública direta e indireta de qualquer dos Poderes da União, dos Estados, do Distrito Federal e dos Municípios obedecerá aos princípios de legalidade, impessoalidade, moralidade, publicidade e eficiência e, também, ao seguinte:

$[\ldots] \S 6^{\circ}$ As pessoas jurídicas de direito público e as de direito privado prestadoras de serviços públicos responderão pelos danos que seus agentes, nessa qualidade, causarem a terceiros, assegurado o direito de regresso contra o responsável nos casos de dolo ou culpa.

\section{Código Civil}

Art. 43. As pessoas jurídicas de direito público interno são civilmente responsáveis por atos dos seus agentes que nessa qualidade causem danos a terceiros, ressalvado direito regressivo contra os causadores do dano, se houver, por parte destes, culpa ou dolo.

$\mathrm{Na}$ seara privada, é necessário distinguir ainda as obrigações assumidas pelo profissional, se de meio ou de resultado, para que se possa individualizar sua responsabilidade. Isto porque, quando a obrigação do profissional for de resultado, ou seja, aquela em que se obriga a alcançar determinado fim como em uma cirurgia plástica estética, terá que arcar com as consequências caso não atinja este resultado. Sua responsabilidade, nesse sentido, será objetiva - sem averiguação se a conduta foi maculada pela culpa. Nas obrigações de meio, o compromisso é de ser diligente na aplicação de todos os recursos disponíveis para a melhor condução do caso, sem vínculo do profissional com o resultado ${ }^{3,4}$.

O número de ações por erro médico vem crescendo ao longo dos anos, sendo em sua maioria relacionadas a procedimentos cirúrgicos ${ }^{5-8}$. A área ortopédica, devido à grande quantidade de cirurgias realizadas na sua prática, encontra-se dentre as especialidades com maior risco. Em levantamento do Conselho Regional de Medicina de São Paulo (CREMESP) realizado no primeiro semestre de 2001 sobre as especialidades com maior número de queixas, a ortopedia figurou em terceiro lugar, perdendo apenas para cirurgia plástica e ginecologia e obstetrícia9. No Conselho Regional de Medicina da Bahia, os processos éticos em ortopedia somavam $10 \%$ do número total de julgados entre 2000 e $2004^{1}$ e, no do Estado de Santa Catarina, o $3^{\circ}$ lugar entre as especialidades com maior número de denúncias ${ }^{8}$.

As cirurgias do quadril representam grande parte do volume de cirurgias ortopédicas no mundo. Com aos bons resultados alcançados com esses procedimentos, sua utilização clínica tem aumentado ao longo dos $\operatorname{anos}^{11}$. Espera-se que o mercado de substituição de articulações aumente $83 \%$ até 2024, com o envelhecimento populacional, aumento das condições de saúde crônicas como artrite reumatoide, osteoartrite e osteoporose ${ }^{12}$. Essas condições facilitam a ocorrência 
Fabricio AS et al. Jurisprudência do Tribunal de São Paulo em ações de responsabilidade civil por erro médico.

de fraturas no quadril, com maior prevalência em mulheres, e cursam com alta morbidade e mortalidade, sendo seu tratamento primariamente cirúrgico. Quando se avalia o panorama do atendimento ao trauma, vê-se que as fraturas do anel pélvico compõem de $2 \%$ a $8 \%$ de todas as lesões do esqueleto, incidência que sobe para $25 \%$ nos politraumatizados e representa fator prognóstico negativo no que diz respeito à morbidade $\mathrm{e}$ à mortalidade ${ }^{13}$.

Mais do que possuir o conhecimento teórico a respeito das obrigações e implicações legais que lhe são peculiares, é importante que o médico ortopedista possa aplicá-lo dentro do cotidiano de seu exercício profissional. Acesso a trabalhos que procuram traçar o perfil das ações em sede judicial são, neste sentido, de extrema importância, pois o profissional, procurando prevenir-se ou já frente a alegações de má prática médica, anseia por informações a respeito de aspectos técnicos e processuais que lhes sejam úteis no exercício profissional ou na sua defesa. De fato, estudo sobre as decisões do Supremo Tribunal Federal e do Superior Tribunal de Justiça demonstra que ações na área da saúde muitas vezes carecem de compreensão do objeto sendo tratado, da extensão e dos limites do direito à saúde ${ }^{14}$.

\begin{abstract}
A análise da jurisprudência, ao longo dos últimos vinte anos, revela os avanços e, ao mesmo tempo, dificuldades que os intérpretes enfrentam para avaliar a demanda de milhares de casos concretos individuais dentro de um contexto comunitário, sendo ainda muito imprecisas e contraditórias as decisões judiciais com o fim de estabelecer o alcance e limites dos direitos sociais.
\end{abstract}

Neste cenário, a análise de estudos que procuram traçar o perfil de ações em ortopedia em sede judicial permite que o profissional entenda os riscos envolvidos nas alegações da má prática e possa melhor embasar sua conduta clínica e cirúrgica. Deste modo, o objetivo deste trabalho foi a avaliação do perfil das decisões de ações de responsabilidade civil por erro médico relacionado a cirurgias ortopédicas de quadril no Estado de São Paulo. Para isso foram selecionados acórdãos desse tipo de ação no período de doze meses junto ao Tribunal de Justiça de São Paulo (TJSP) no ano de 2018.

\section{MÉTODO}

Foi realizado levantamento dos acórdãos relacionados a cirurgias de quadril por meio de pesquisa de palavras-chave no instrumento de busca do site de jurisprudência do Tribunal de Justiça do Estado de São Paulo com os termos de pesquisa "erro médico" e "quadril" (https://esaj.tjsp.jus.br/ cjsg/consultaCompleta.do). $\mathrm{O}$ acesso foi realizado em $02 / 07 / 2019$. O período pesquisado foi de decisões entre $01 / 01 / 2018$ e $31 / 12 / 2018$. Foram selecionados os campos "acórdãos" e " $2^{\circ}$ grau".

As variáveis analisadas foram o número de decisões sobre a matéria, o mérito sendo apreciado em segundo grau e a procedência dos pedidos.

Os acórdãos foram lidos na íntegra e as informações obtidas foram organizadas em tabela descritiva contendo: número do processo no Tribunal de Justiça de São Paulo, comarca de origem, data do julgamento, mérito apreciado, partes envolvidas, responsabilidades apuradas no processo, decisão proferida em segunda instância e o valor a ser indenizado, se aplicável.

\section{RESULTADOS}

Foram encontrados 35 acórdãos com os critérios de inclusão da pesquisa. Dentre estes resultados, 21 foram excluídos por não se referirem diretamente a procedimentos cirúrgicos do quadril, restando 14 casos, todos utilizados na amostra.

Os dados sobre o motivo da lide, os demandados (médicos, hospitais, seguradora/plano de saúde, Estado), a natureza (pública/privada) e procedência da demanda foram resumidos na Tabela 1 .

Dentre os casos analisados, observa-se que a maioria das decisões é referente a artroplastias do quadril $(n=6)$ e fixações cirúrgicas de fraturas $(n=5)$ em que houve complicações ou sequelas. As outras decisões tratavam de complicações de correção cirúrgica de displasia congênita do quadril $(n=2)$ e epifisiolise $(n=1)$.

Analisando-se a origem das ações percebe-se que a maioria tramitou nas câmaras privadas $(n=11)$. Das ações de câmaras públicas, uma não havia chegado à resolução do mérito, sendo redistribuída para a câmara privada, posto que um dos réus era pessoa jurídica de direito privado. No âmbito privado, a maior parte das decisões $(\mathrm{n}=9)$ envolveu tanto o(s) médico(s) quanto o hospital onde foi realizado o procedimento. Nestes casos, vê-se que a conduta do médico foi avaliada por meio de perícia para a determinação de culpa e nexo de causalidade, caracterizando a responsabilidade subjetiva. Os hospitais envolvidos foram responsabilizados nos casos em que os médicos foram considerados culpados do resultado adverso. Em uma das decisões, apenas o hospital foi condenado a pagar indenização, pois tratava-se de infecção hospitalar adquirida no pós-operatório. Em apenas um caso a lide envolveu apenas o médico. Ainda quanto às decisões das câmaras privadas, as seguradoras/planos de saúde fizeram parte do pleito em $63,6 \%$ dos casos, juntamente com os médicos e hospitais réus. 
Fabricio AS et al. Jurisprudência do Tribunal de São Paulo em ações de responsabilidade civil por erro médico.

Tabela 1 - Decisões do Tribunal de Justiça do Estado de São Paulo no ano de 2018 relacionadas a lides de responsabilidade civil envolvendo má prática em cirurgias do quadril. $n=14$

\begin{tabular}{|c|c|c|c|c|c|c|c|c|c|}
\hline \multirow[b]{2}{*}{$\mathrm{N}^{\circ}$ do acórdão e data } & \multirow[b]{2}{*}{ 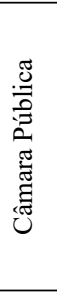 } & \multirow[b]{2}{*}{ 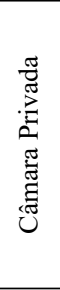 } & \multirow[b]{2}{*}{ Motivo da lide } & \multicolumn{4}{|c|}{$\begin{array}{l}\text { Réus no processo } \\
\text { originário }\end{array}$} & \multicolumn{2}{|c|}{ Decisão } \\
\hline & & & & 莺 & 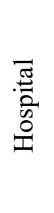 & 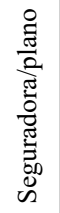 & 胥 & 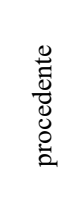 & 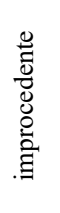 \\
\hline 0012775-79.2012.8.26.0114 & & $\mathrm{X}$ & $\begin{array}{l}\text { Displasia congênita do quadril } \\
\text { Complicações vasculares }\end{array}$ & $\mathrm{X}$ & $\mathrm{X}$ & & & $*$ & \\
\hline $1006070-95.2014 .8 .26 .0011^{16}$ & & $\mathrm{X}$ & $\begin{array}{l}\text { Osteossíntese de fratura de fêmur } \\
\text { Fixação inadequada }\end{array}$ & $\mathrm{X}$ & $\mathrm{X}$ & $\mathrm{X}$ & & $\mathrm{X}$ & \\
\hline $1044692-20.2014 .8 .26 .0053^{17}$ & $\mathrm{X}$ & & $\begin{array}{l}\text { Artroplastia do quadril por fratura } \\
\text { Complicações relacionadas à prótese }\end{array}$ & & & & $\mathrm{X}$ & & $\mathrm{X}$ \\
\hline $0027656-46.2011 .8 .26 .0001^{18}$ & & $\mathrm{X}$ & $\begin{array}{l}\text { Displasia congênita do quadril + } \\
\text { mielomeningocele } \\
\text { Perda da força em MMII }\end{array}$ & $\mathrm{X}$ & $\mathrm{X}$ & & & & $\mathrm{X}$ \\
\hline $1092439-82.2015 .8 .26 .0100^{19}$ & & $\mathrm{X}$ & $\begin{array}{l}\text { Artroplastia do quadril } \\
\text { Complicações relacionadas à prótese }\end{array}$ & $\mathrm{X}$ & & & & \multicolumn{2}{|c|}{$\begin{array}{l}\text { Procedente em } \\
\text { parte }\end{array}$} \\
\hline 0034403-29.2009.8.26.0309²0 & $\mathrm{X}$ & & $\begin{array}{l}\text { Osteossíntese de fratura do quadril } \\
\text { Assimetria do quadril }\end{array}$ & $\mathrm{X}$ & $\mathrm{X}$ & $\mathrm{X}$ & $\mathrm{X}$ & & $\mathrm{X}$ \\
\hline $0027129-23.2000 .8 .26 .0602^{21}$ & & $\mathrm{X}$ & $\begin{array}{l}\text { Osteossíntese de fratura do quadril } \\
\text { Complicações da cirurgia }\end{array}$ & $\mathrm{X}$ & $\mathrm{X}$ & $\mathrm{X}$ & & & $\mathrm{X}$ \\
\hline $1012878-09.2014 .8 .26 .0564^{22}$ & & $\mathrm{X}$ & $\begin{array}{l}\text { Osteossíntese de fratura de fêmur } \\
\text { Complicações infecciosas }\end{array}$ & $\mathrm{X}$ & $\mathrm{X}$ & $\mathrm{X}$ & & & $\mathrm{X}$ \\
\hline $1004049-35.2014 .8 .26 .0048^{23}$ & & $\mathrm{X}$ & $\begin{array}{l}\text { Artroplastia total do quadril por fratura. } \\
\text { Infecção hospitalar com óbito }\end{array}$ & & $\mathrm{X}$ & & & \multicolumn{2}{|c|}{$\begin{array}{l}\text { Procedente em } \\
\text { parte }\end{array}$} \\
\hline $1035526-20.2014 .8 .26 .0002^{24}$ & & $\mathrm{X}$ & $\begin{array}{l}\text { Osteossíntese de fratura do fêmur } \\
\text { Complicações infecciosas }\end{array}$ & $\mathrm{X}$ & $\mathrm{X}$ & $\mathrm{X}$ & & & $\mathrm{X}$ \\
\hline 0047896-65.2009.8.26.005325 & $\mathrm{X}$ & & $\begin{array}{l}\text { Artroplastia total do quadril } \\
\text { TVP por falta de profilaxia }\end{array}$ & $\mathrm{X}$ & $\mathrm{X}$ & & & $\mathrm{X}$ & \\
\hline $1083892-87.2014 .8 .26 .0100^{26}$ & & $\mathrm{X}$ & $\begin{array}{l}\text { Revisão de prótese do quadril } \\
\text { Embolia gordurosa com óbito }\end{array}$ & $\mathrm{X}$ & $\mathrm{X}$ & & & & $\mathrm{X}$ \\
\hline 0515891-06.1997.8.26.010027 & & $\mathrm{X}$ & $\begin{array}{l}\text { Correção de epifisiólise do fêmur } \\
\text { Complicações pós cirúrgicas }\end{array}$ & $\mathrm{X}$ & $\mathrm{X}$ & $\mathrm{X}$ & & & $\mathrm{X}$ \\
\hline $0009180-02.2012 .8 .26 .0008^{28}$ & & $\mathrm{X}$ & $\begin{array}{l}\text { Artroplastia total do quadril } \\
\text { Soltura de prótese }\end{array}$ & $X$ & $\mathrm{X}$ & $\mathrm{X}$ & & \multicolumn{2}{|c|}{$\begin{array}{l}\text { Procedente em } \\
\text { parte }\end{array}$} \\
\hline
\end{tabular}

Dentre as onze decisões das câmaras privadas analisadas, apenas quatro foram consideradas procedentes total ou parcialmente, com consequente indenização dos autores pelo dano. Em um dos casos não houve decisão final sobre a responsabilidade médica no momento do acórdão por haver controvérsias nos laudos periciais, sendo o julgamento convertido em diligência e solicitada perícia complementar.

No âmbito público, duas ações foram consideradas improcedentes e uma procedente, com desfecho favorável ao autor.

\section{DISCUSSÃO}

O quadril é uma das articulações mais importantes do corpo humano. Ele participa da conexão entre a parte superior do nosso corpo (cabeça, tronco e membros superiores) e os membros inferiores, responsáveis por sustentar todo o peso e promover a locomoção. A articulação do quadril é conhecida como uma diartrose do tipo esferoide, ou seja, uma articulação na qual a superfície óssea é recoberta por cartilagem e banhada por líquido sinovial, possibilitando movimentos em vários eixos $^{29}$. Além dos ossos, na região do quadril, existem diversos músculos (dentre os maiores e mais fortes do corpo) que atravessam ou têm inserção/origem nesta região ${ }^{30}$. Nessa área também se encontram grandes vasos sanguíneos e nervos, e há relação de proximidade com a coluna vertebral. Devido à grande quantidade de estruturas importantes em íntima relação, as dores do 
Fabricio AS et al. Jurisprudência do Tribunal de São Paulo em ações de responsabilidade civil por erro médico.

quadril podem ser facilmente confundidas com dores nas regiões adjacentes, como coluna e abdome, verdadeiro desafio de avaliação, diagnóstico e tratamento destas patologias.

Por ser articulação de carga, o quadril está sujeito a forças mecânicas de diversas naturezas, que podem originar diferentes tipos de lesões. Muitas das patologias relacionadas melhoram apenas com o tratamento conservador, porém algumas somente são resolvidas com intervenção cirúrgica ${ }^{30}$.

As cirurgias de quadril representam uma parcela importante das cirurgias ortopédicas em geral. Elas podem ser divididas em dois grandes grupos: as cirurgias por via aberta, que envolvem o tratamento de fraturas, artrose, correções de deformidades, entre outras; e as por via artroscópica, que se dividem em intervenções terapêuticas, tendo como principais indicações as lesões labrais, impacto femoroacetabular e lesões do ligamento redondo, e as intervenções diagnósticas, para avaliação da cartilagem nos casos de osteonecrose, coleta de tecidos para culturas e avaliação de soltura de implantes intra-articulares ${ }^{32}$.

As cirurgias por via aberta mais frequentemente realizadas são a artroplastia do quadril e a osteossíntese de fraturas $^{32}$. A artroplastia do quadril é cirurgia com alto índice de satisfação pós-operatória (mais de 90\%) e baixos índices de complicações ${ }^{29,31}$. Consiste na troca dos componentes ósseos afetados por alguma patologia (artrite reumatoide, necrose da cabeça femoral, artrose idiopática, fraturas, entre outras) por componentes artificiais no intuito de restabelecer a função da articulação do quadril alterado e, consequentemente, a melhora da dor, da mobilidade e da locomoção ${ }^{29}$. A patologia que mais frequentemente acomete o quadril levando o paciente a ser submetido a esse procedimento é a artrose primária do quadril, porém existem diversas outras que levam a um quadro de dor crônica com indicação cirúrgica, tais como osteonecrose da cabeça do fêmur, artrites inflamatórias, sequela de fraturas no acetábulo ou no fêmur proximal, deformidades congênitas ou adquiridas na infância ${ }^{29}$. Os subgrupos cirúrgicos são a artroplastia total, quando toda a articulação do quadril (tanto fêmur quanto o acetábulo) é trocada; artroplastia parcial, quando apenas o componente femoral é trocado, sem intervenção na região acetabular; e a artroplastia de recapeamento, onde apenas a cabeça do fêmur e superfície acetabular são recobertas, preservando um estoque ósseo. Outra diferenciação que pode ser feita refere-se ao tipo de fixação do material cirúrgico ao osso, nesse aspecto, as próteses podem ser do tipo cimentada, quando tanto o componente femoral quanto o acetabular são fixados no osso com um cimento próprio para isso; do tipo não cimentada, quando nenhum dos componentes é fixado com uso de cimento, nesse caso o material é rugoso e adere por pressão ou com o uso de parafusos, e por fim, podem ser do tipo híbrida, quando apenas um dos componentes (acetábulo ou haste femoral) é fixado com o uso de cimento e o outro não ${ }^{32}$.

Embora seguras e com infrequentes complicações, as artroplastias do quadril não são isentas de efeitos adversos que, na sua maioria, podem ser prevenidos ou tratados se reconhecidos prontamente. Estes podem ser divididos em complicações imediatas e a médio ou longo prazo $^{29}$. As complicações imediatas ou a curto prazo incluem fratura intraoperatória, lesões neurais ou vasculares, encurtamento de membro, infecção do leito cirúrgico, embolia gordurosa e trombose venosa profunda, o que motiva a utilização de anticoagulantes profiláticos pré-cirurgicos ${ }^{33}$. As complicações tardias incluem processos infecciosos envolvendo a prótese, seu deslocamento, osteólise e desgaste dos ossos do fêmur e da bacia, fratura periprotética e soltura da prótese ${ }^{29}$.

As osteossínteses ou fixações de fraturas são cirurgias com indicações bastante precisas. Como o nome diz, são indicadas nos casos de fraturas do quadril (fratura do colo do fêmur, fraturas da cabeça do fêmur, fraturas do acetábulo ou fraturas transtrocanterianas). Nestes casos podem ser usadas diversas técnicas cirúrgicas e variados tipos de implantes, de acordo com a preferência e destreza do cirurgião ortopédico que irá conduzir o caso e de acordo com o tipo de fratura que o paciente apresenta ${ }^{34}$.

É importante lembrar que os quadros clínicos anteriores à cirurgia são usualmente complexos, caso contrário, optar-se-ia por terapêutica conservadora. Os pacientes e profissionais muitas vezes travam batalhas, que não raro chegam aos tribunais, no intuito de obter autorização por parte dos planos de saúde para o uso de materiais e equipamentos, de acordo com a melhor prática técnica para o caso e a capacitação do cirurgião. Serras, por exemplo, apresentam características ergonômicas específicas de cada marca, e devem ser operadas por profissionais habilitados ao uso daquele equipamento específico, não devendo o profissional se sujeitar ao uso daquelas para as quais não for capacitado. A própria demora para a liberação dos materiais, ou para a liberação do paciente para hospital com equipamentos adequados, pode agravar o caso e ser passível de indenização ${ }^{35}$. O entendimento dos tribunais neste sentido é cristalino, balizado por resolução normativa da Agência Nacional de Saúde Suplementar ${ }^{36}$ :

AGRAVO DE INSTRUMENTO - Plano de Saúde Ação de Obrigação de

Fazer - Decisão que indeferiu o pedido de tutela de urgência, para o fim de compelir a ré a autorizar e custear os materiais necessários para o procedimento cirúrgico - Inconformismo da autora reiterando a necessidade e urgência dos materiais necessários Cabimento - Cirurgia prescrita por médico competente - Inadmissibilidade de interferência da operadora de 
Fabricio AS et al. Jurisprudência do Tribunal de São Paulo em ações de responsabilidade civil por erro médico.

plano de saúde sobre o tratamento a ser ministrado à autora - Tutela que deve ser concedida, para o fim de compelir a ré autorizar e custear os materiais necessários a intervenção cirúrgica, conforme indicação médica, a ser realizada em hospital credenciado, no prazo de dez dias, sob pena de multa diária de $\mathrm{R} \$ 1.000,00$ (mil reais), até o limite de $\mathrm{R} \$ 50.000,00$ (cinquenta mil reais) - Recurso provido. TJSP AI 213190978.2016.8.26.0000. Relator: Des. José Aparício Coelho Prado Neto. $9^{\text {a }}$ Câmara de Direito Privado; Foro Regional XI - Pinheiros - $3^{\text {a }}$ Vara Cível. Julgado em: $25 / 10 / 2016^{37}$.

Resolução Normativa da ANS no 387 de 28/10/2015 [...] I - cabe ao médico ou ao cirurgião-dentista assistente a prerrogativa de determinar as características (tipo, matéria-prima e dimensões) das órteses, das próteses e dos materiais especiais - OPME necessários à execução dos procedimentos contidos nos Anexos desta Resolução Normativa;

II - o profissional requisitante deve, quando assim solicitado pela operadora de plano privado de assistência à saúde, justificar clinicamente a sua indicação e oferecer pelo menos 03 (três) marcas de produtos de fabricantes diferentes, quando disponíveis, dentre aquelas regularizadas junto à ANVISA, que atendam às características especificadas ${ }^{36}$;

\section{TJPE}

54. É abusiva a negativa de cobertura de próteses e órteses, vinculadas ou consequentes de procedimento cirúrgico, ainda que de cobertura expressamente excluída ou limitada, no contrato de assistência à saúde ${ }^{38}$.

\section{TJPA}

30. Ainda que o contrato seja firmado posteriormente à lei 9.656, é abusiva a negativa de cobertura de próteses, órteses e materiais especiais diretamente ligados ao procedimento cirúrgico ${ }^{39}$.

\section{TJRJ}

112. É nula, por abusiva, a cláusula que exclui de cobertura a órtese que integre, necessariamente, cirurgia ou procedimento coberto por plano ou seguro de saúde, tais como "stent" e marcapasso ${ }^{40}$.

211. Havendo divergência entre o seguro saúde contratado e o profissional responsável pelo procedimento cirúrgico, quanto à técnica e ao material a serem empregados, a escolha cabe ao médico incumbido de sua realização. ${ }^{41}$

340. Ainda que admitida a possibilidade de o contrato de plano de saúde conter cláusulas limitativas dos direitos do consumidor, revela se abusiva a que exclui o custeio dos meios e materiais necessários ao melhor desempenho do tratamento da doença coberta pelo plano ${ }^{42}$.

$\mathrm{Na}$ amostra estudada, observa-se que as lides que chegaram ao tribunal de São Paulo em 2018 foram relacionadas a complicações cirúrgicas, sendo estas previstas na literatura médica. $\mathrm{O}$ que transparece nos acórdãos é a inequívoca insatisfação dos autores com o mau resultado, com incerteza a respeito do real esclarecimento sobre os riscos cirúrgicos por parte da equipe médica, dever ético ${ }^{43}$ e legal profissional. No estado de São Paulo, inclusive, este dever é explicito na lei Mario Covas ${ }^{44}$ e no Código de Saúde Estadual (Lei Complementar n. 791/95) ${ }^{45}$. Não deve ser adstrito àquele documento padrão genérico do hospital, e demanda comunicação efetiva entre o paciente, sua família e o profissional, a respeito dos riscos e opções cirúrgicas. A elaboração de um termo de consentimento livre e esclarecido, em terminologia compreensível, é o mínimo esperado por profissional da área médica que realizará qualquer conduta no paciente. A falta de informação, que por si só é indenizável, parece impulsionar os outros pedidos da mesma ação.

Deve o ortopedista, também, registrar no prontuário do paciente os pedidos encaminhados para autorização de materiais junto ao plano de saúde, e mantê-lo informado sobre este processo. Nestes pedidos, a urgência ou emergência médicas precisam estar visivelmente explícitas, com justificativa de forma extensiva dos possíveis danos quanto ao seu não acolhimento, afastando a responsabilidade do médico em não descrever corretamente a situação, caso dela resulte agravo $^{46}$. Assim a jurisprudência:

\section{PLANO DE SAÚDE PROCEDIMENTO CIRÚRGICO PRESCRIÇÃO QUE NÃO FOI DADA EM REGIME DE URGÊNCIA OU EMERGÊNCIA Autorização antes mesmo do deferimento da tutela provisória e dentro do prazo regulamentar de 21 dias úteis, a contar da solicitação Inexistência de ato ilícito Decisão mantida Recurso improvido." (TJSP. Apelação $\mathrm{n}^{\circ}$ 1017992-83.2016.8.26.0005. 5 $5^{\text {a }}$ Câmara de Direito Privado. Relator: Des. Fábio Podestá. Julgado em: $11 / 10 / 17)^{47}$}

É certo que, comprovado o efeito adverso desprovido de culpa nas condutas médicas da amostra estudada, não houve reconhecimento do dever de indenizar ${ }^{26}$, como no caso em que o paciente foi a óbito, por embolia gordurosa após revisão de artroplastia do quadril. Nos casos procedentes $(n=5)$, houve culpa dos profissionais pela inobservância de condutas descritas na literatura e consideradas como consenso para determinado procedimento, como no caso em que se sucedeu trombose venosa por não ter sido orientada profilaxia adequada para esta possível complicação ${ }^{25}$. Em outro caso, a técnica cirúrgica foi considerada inadequada pela perícia judicial, com complicações posteriores, como migração do material de síntese e desvio do membro ${ }^{16}$. No caso em que houve óbito por infecção hospitalar no pós-operatório ${ }^{23}$ não foi atribuída culpa ao médico, 
Fabricio AS et al. Jurisprudência do Tribunal de São Paulo em ações de responsabilidade civil por erro médico.

visto que, em tese, o ocorrido é de responsabilidade do hospital, respondendo este objetivamente. Entretanto, é importante que o médico demonstre nestes casos adesão ao protocolo de antibióticoprofilaxia cirúrgica ${ }^{48}$ e atenção ao quadro clínico, aos sinais, sintomas e riscos inerentes ao quadro específico durante a internação com vistas à pronta atuação em casos de infecção, em conjunto com a equipe de infectologia do hospital, justificando, no prontuário, o distanciamento de protocolos de antibioticoterapias reconhecidos, quando necessário, fundamentado-se em exames competentes. Mais da metade das infecções hospitalares estão relacionadas a patógenos resistentes do local e a tratamento inapropriado, este de responsabilidade do profissional ${ }^{49,50}$.

Quanto aos valores indenizatórios, sabe-se que são variáveis e dependem de inúmeros fatores para sua determinação, alguns de difícil apreciação, como a natureza e a extensão do dano, as características da vítima e o sofrimento imposto à vítima e seus familiares ${ }^{3}$. Considerando-se as lides nas quais foi imposto o pagamento de danos morais, vê-se que o valor mais alto ( $\mathrm{R} \$ 50.000,00)$ foi concedido no caso em que houve óbito por infecção hospitalar. A menor indenização por danos morais concedida foi de $\mathrm{R} \$ 20.000,00$, no caso de uma senhora idosa com diversas comorbidades, evoluiu com luxação de prótese do quadril, sendo a culpa do médico parcialmente reconhecida.

A respeito da participação dos planos de saúde nas lides, entende-se que estes respondem pelos atos de seus médicos credenciados, conforme decisão do Supremo
Tribunal de Justiça de $2001^{51}$. Já nas situações onde há livre escolha do profissional, com posterior reembolso de valores, não há responsabilidade solidária da seguradora, que não deve fazer parte da lide de má-prática, exceto se houver participado do dano causado, como negativa de materiais requisitados pelo profissional ou atraso em seu fornecimento.

\section{CONCLUSÃO}

As cirurgias do quadril representam uma grande parte das cirurgias ortopédicas realizadas no Brasil. A análise dos acórdãos relacionados a procedimentos cirúrgicos do quadril no Tribunal de Justiça do Estado de São Paulo no ano de 2018 indica que na maioria dos casos não houve responsabilização do médico, após avaliação pericial. A má-prática foi estabelecida em 35,7\% das lides $(n=5)$, sendo caracterizada pela inobservância de condutas ou normas consolidadas na literatura.

Nas ações de serviços públicos, muito embora os médicos não devessem fazer parte do pleito por ser a responsabilidade diretamente do ente público, estes não foram afastados da lide.

A fundamentação das decisões demonstrou a importância da boa relação médico-paciente, tanto dialogada como nos termos escritos, sendo o termo de consentimento livre e esclarecido um documento médico legal importante nas avaliações periciais, visto que os agravos que motivaram as lides foram desencadeados por complicações cirúrgicas previsíveis.

Fabricio AS, Fabricio SC, Motta MV. Rulings of the Court of Appeal of the State of São Paulo in cases of hip surgery malpractice. Saúde, Ética \& Justiça. 2019;24(2):74-83.

\begin{abstract}
The rate of medical malpractice suits is rising in Brazil. These suits are mostly related to surgical procedures. Due to the nature of their field, orthopedic surgeons feature among the most sewed medical professionals. Hip surgery represents a large portion of the orthopedic surgery practice. This research evaluated the rulings of the Regional Court of the State of São Paulo, analyzing the profile of malpractice lawsuits involving hip surgery, the nature of the cases and their decisions. A total of 14 cases were directly related to hip surgery. These cases were evaluated according to the matter in question, defendants and their alleged responsibility, decision of the appeal and damage compensation fees if applicable. Most of the cases (57.1\%) were dismissed and the physicians acquitted of charges. Of the five cases considered valid, in four the physician was found liable and in one case only the hospital was held responsible. Medical malpractice was characterized due to lack of observance to current accepted scientific practices.
\end{abstract}

KEY WORDS: Orthopedic Procedures; Medical Errors; Consumer Advocacy ; Malpractice; Imprudence; Professional Misconduct; Jurisprudence; Liability, Legal ; Damage Liability.

\title{
REFERÊNCIAS
}

1. Brasil. Presidência da República, Subchefia para Assuntos Jurídicos. Lei $\mathrm{n}^{\circ} 10.406$ de 10 de janeiro de 2002. Institui o Código Civil [Internet]. Brasília, DF; 2002. [Acesso em 2019 nov. 10]. Disponível em: http://www.planalto.gov. br/ccivil_03/leis/2002/L10406compilada.htm
2. Brasil. Presidência da República, Subchefia para Assuntos Jurídicos. Constituição da República Federativa do Brasil de 1988 [Internet]. Brasília, DF; 1988. [Acesso em 2019 nov. 10]. Disponível em: http://www.planalto.gov.br/ ccivil_03/constituicao/constituicao.htm 
Fabricio AS et al. Jurisprudência do Tribunal de São Paulo em ações de responsabilidade civil por erro médico.

3. Kfouri Neto M. Responsabilidade civil do médico. $2^{\mathrm{a}}$ ed. São Paulo: Revista dos Tribunais; 1996.

4. Nery Junior N. Os princípios gerais do Código Brasileiro de Defesa do Consumidor. Revista de Direito do Consumidor. 1992;3:44-77.

5. Garfinkel A. Responsabilidade civil por erro médico segundo a jurisprudência do Tribunal de Justiça do Estado de São Paulo (síntese). Revista Direito GV. 2007;3(2):3758 .

6. Gomes TR, de Sá MCDP. O erro médico sob o olhar do Judiciário: uma investigação no Tribunal de Justiça do Distrito Federal e Territórios. Cad Ibero-Amer Dir Sanit. 2017;6(1):72-85. DOI: https://doi.org/10.17566/ciads. v6i1.362

7. Braga IF, Ertler LZ, Aquino RM, da Fonseca e Silva BA, Pereira RB. Responsabilização penal do médico no Tribunal de Justiça do Estado de São Paulo. Einstein (São Paulo). 2018;16(1):1-5. DOI: https://doi.org/10.1590/ S1679-45082018AO4060

8. Koeche LG, Cenci I, Bortoluzzi MC, Bonamigo EL. Prevalência de erro médico entre as especialidades médicas nos processos julgados pelo Conselho Regional de Medicina do Estado de Santa Catarina. ACM arq catarin med [Internet]. 2013 [Acesso em 2019 nov. 2];42(4):45-53. Disponível em: http://www.acm.org.br/ revista/pdf/artigos/1257.pdf

9. Udelsmann A. Responsabilidade civil, penal e ética dos médicos. Rev Assoc Med Bras [Internet]. 2002 [Acesso em 2019 nov. 2];48(2):172-82. Disponível em: http://www. scielo.br/scielo.php?script=sci_arttext\&pid $=\mathrm{S} 0104-$ 42302002000200039\&lng=en\&nrm=iso. DOI: https:// doi.org/10.1590/S0104-42302002000200039

10. Bitencourt AGV, Neves NMBC, Neves FBCS, Brasil ISPS, Santos LSC. Análise do erro médico em processos ético-profissionais: implicações na educação médica. Rev Bras Educ Med [Internet]. 2007 [Acesso em 2019 nov. 2];31(3):223-8. Disponível em: http://www.scielo.br/pdf/ rbem/v31n3/04.pdf. DOI: https://doi.org/10.1590/S010055022007000300004

11. Judas F, Dias R, Figueiredo H. Implantes em cirurgia ortopédica [Internet]. Coimbra: Clínica Universitária de Ortopedia, HUC; 2008 [Acesso em 2019 nov. 2]. Disponível em: http://hdl.handle.net/10400.4/1200

12. Energias Market Research. Global Joint Replacement Market is expected to witness a CAGR of $7.7 \%$ during 2018-2014 [Internet]. New York; 2018 [Acesso em 2019 nov. 2]. Disponível em: https://www.globenewswire. com/news-release/2018/05/15/1502380/0/en/GlobalJoint-Replacement-Market-is-expected-to-Witness-aCAGR-of-7-7-during-2018-2024.html

13. Freitas CD, Garotti JER, Nieto J, Guimarães RP, Ono NK, Honda E, Polesello GC. Houve mudanças na incidência e na epidemiologia das fraturas do anel pélvico nas últimas décadas? Rev Bras Ortop. 2013;48(6):475-81. DOI: https://doi.org/10.1016/j.rbo.2012.10.013

14. Werner PUP. O direito social e o direito público subjetivo à saúde: o desafio de compreender um direito com duas faces. Revista de Direito Sanitário. 2008;9(2):92131. DOI: https://doi.org/10.11606/issn.2316-9044. v9i2p92-131

15. São Paulo. Tribunal de Justiça de São Paulo. $10^{a}$ Câmara de Direito Privado; Comarca - Foro de Campinas, SP. Processo 0012775-79.2012.8.26.0114. Maria Castor de Moura, José Carlos Affonso Ferreira e Fundação Centro Médico de Campinas. Relator: Elcio Trujillo. Acórdão, 23 out. 2018. Diário de Justiça do Estado de São Paulo - Judicial - 2 ${ }^{\mathrm{a}}$ Instância. p. 2217.

16. São Paulo. Tribunal de Justiça de São Paulo. $30^{\mathrm{a}}$ Câmara Extraordinária de Direito Privado; Foro Regional XI - Pinheiros - 2a Vara Cível. Apelação 100607095.2014.8.26.0011. Arthur Reis Anjos, Katia de Jesus Reis Anjos e Hospital Israelita Albert Einstein. Relator: Araldo Telles. Acórdão, 04 set. 2018. Diário de Justiça do Estado de São Paulo - Judicial - $1^{\text {a }}$ Instância - Capital. p. 687.

17. São Paulo. Tribunal de Justiça de São Paulo. Foro - Foro Central - Fazenda Pública/Acidentes da Comarca de São Paulo, SP. Processo 1044692-20.2014.8.26.0053. Eliana Paulo dos Santos, Estado de São Paulo e Fazenda Pública do Estado de São Paulo. Relator: Vera Agrisani. Acórdão, 30 ago. 2018.

18. São Paulo. Tribunal de Justiça de São Paulo. Foro - Foro Regional I - Santana da Comarca de São Paulo, SP. Processo 0027656-46.2011.8.26.0001. Dayse Aparecida Oliveira Fernandes e Antônio Carlos dos Santos. Relator: Salles Rossi. Acórdão, 30 jul. 2018. Diário de Justiça do Estado de São Paulo - Judicial - $2^{\mathrm{a}}$ Instância - Capital. p. 156.

19. São Paulo. Tribunal de Justiça de São Paulo. Foro - Foro Central Cível da Comarca de São Paulo, SP - $3^{\mathrm{a}}$ Câmara Direito Privado. Processo 1092439-82.2015.8.26.0100. Luiz César Ludovice, Luiz Paulo Burckauser, Maria Cândida da Cunha Burckauser e Maria de Lourdes da Cunha Burckauser. Relator: Carlos Alberto de Salles. Acórdão, 26 jun. 2018. Diário de Justiça do Estado de São Paulo - Judicial - 2a Instância - Capital. p. 1972.

20. São Paulo. Tribunal de Justiça de São Paulo. Comarca: Jundiaí; Vara: 4a . Vara Cível. Processo 003440329.2009.8.26.0309. Antônia Benedita Cardoso de Lima, Christian Alexandre Merenciano, Hospital São Vicente de Paulo, IRB - Brasil Resseguros S/A, INSS - Instituto Nacional do Seguro Social, Luiz Carlos Bianchi, Nobre Seguradora do Brasil S/A e Santa Casa de Misericórdia. Relator: Marrey Uint. Acórdão, 19 jul. 2018. Diário de Justiça do Estado de São Paulo - Judicial - $2^{\mathrm{a}}$ Instância. p. 1624.

21. São Paulo. Tribunal de Justiça de São Paulo. Comarca: Sorocaba; Vara: $1^{\text {a }}$ Vara Cível. Processo 002712923.2000.8.26.0602. Ana Fátima de Oliveira Beda, Aparecida de Oliveira, Aparecido de Oliveira, Eduardo de Oliveira, Espólio Apparecida de Oliveira, João Batista de Oliveira, José Luiz de Oliveira, Julieta Tadeu de Oliveira, Marcio de Oliveira, Marcos Luis de Oliveira, Maria Elizabeth de Oliveira Arruda, Mercia Maria de Oliveira Leite, Erick Vecina, Fabio Luis Fernandes, 
Fabricio AS et al. Jurisprudência do Tribunal de São Paulo em ações de responsabilidade civil por erro médico.

Hospital Modelo de Sorocaba, IVO Vecina Martins e Notre Dame Intermédica Saúde S/A. Relator: Rosangela Telles. Acórdão, 25 jun. 2018. Diário de Justiça do Estado de São Paulo - Judicial - $2^{\mathrm{a}}$ Instância. p. 120.

22. São Paulo. Tribunal de Justiça de São Paulo. Comarca: São Bernardo do Campo; Vara: $9^{\text {a }}$ Vara Cível. Processo 1012878-09.2014.8.26.0564. ACE Seguradora S.A, Hospital Ifor Ltda., José Tiago Monteiro de Andrade e Vitor Carvalho Lopes. Relator: Miguel Brandi. Acórdão, 19 jun. 2018. Diário de Justiça do Estado de São Paulo - Judicial - 2 Instância. p. 243.

23. São Paulo. Tribunal de Justiça de São Paulo. $7^{\text {a }}$ Câmara de Direito Privado; Foro de Atibaia; 2a Vara Cível. Processo 1004049-35.2014.8.26.0048. Bruno Iannone Amaral, Associação LAR São Francisco de Assis NA Providência de Deus (Hospital Universitário São Francisco NA Providência de Deus), Casa Nossa Senhora da PAZ Husf, Casa de Nossa Senhora da PAZ - Ação Social Franciscana, PRO Saúde Santa Casa de Atibaia, Lourdes Iannone e Pró-Saude Associação Beneficente de Assistência Social e Hospitalar. Relator: Mary Grün. Acórdão, 23 mai. 2018. Diário de Justiça do Estado de São Paulo - Judicial - 2a Instância. p. 2515.

24. São Paulo. Tribunal de Justiça de São Paulo. Foro - Foro Regional II - Santo Amaro da Comarca de São Paulo, SP. Processo 1035526-20.2014.8.26.0002. Ameplan Assistência Médica Planejada LTDA, Hairton Campos, Hospital e Maternidade Vida'S S/C LTDA e Joaquim Camelo Silva. Relator: James Siano. Acórdão, 22 mai. 2018. Diário de Justiça do Estado de São Paulo - Judicial - 2 Instância. p. 1960.

25. São Paulo. Tribunal de Justiça de São Paulo. Comarca: São Paulo; Vara: $9^{\text {a }}$ Vara de Fazenda Pública. Processo 0047896-65.2009.8.26.0053. Lúcia Helena Ferreira Skromov, Hospital do Servidor Público Municipal (HSPM) e Reinaldo Massis. Relator: Vicente de Abreu Amadei. Acórdão, 03 abr. 2018. Diário de Justiça do Estado de São Paulo - Judicial - 2a Instância. p. 232.

26. São Paulo. Tribunal de Justiça de São Paulo. Comarca: São Paulo; Vara: $3^{\text {a }}$ Vara Cível. Processo $1083892-$ 87.2014.8.26.0100. Claudete Vieira Sampaio Rezende de Almeida, Hospital São Luiz, Lucas Leite Ribeiro e Marcos Hajime Tanaka. Relator: Rosangela Telles. Acórdão, 14 mar. 2018. Diário de Justiça do Estado de São Paulo - Judicial - $2^{\mathrm{a}}$ Instância. p. 180.

27. São Paulo. Tribunal de Justiça de São Paulo. Foro - Foro Central Cível da Comarca de São Paulo, SP - $3^{\text {a Câmara }}$ Direito Privado. Processo 0515891-06.1997.8.26.0100. Francisco Cosme de Zan, Amico Assistência Médica A Indústria e Comércio LTDA, Gregório Pugliese e Csortopedia Especializada LTDA. Relator: Alexandre Marcondes. Acórdão, 09 mar. 2018. Diário de Justiça do Estado de São Paulo - Judicial - 2a Instância. p. 1756.

28. São Paulo. Tribunal de Justiça de São Paulo. Foro - Foro Regional VIII - Tatuapé da Comarca de São Paulo, SP $30^{\mathrm{a}}$ Câmara Extraordinária da Seção de Direito Privado. Processo 0009180-02.2012.8.26.0008. Glória Carvalho Silva Santos, Igesp S A Centro Médico e Cirúrgico
Instituto de Gastroenterologia de São Paulo, Nobre Seguradora do Brasil S A e Fabio Ferraz do Amaral Ravaglia. Relator: Enio Zuliani. Acórdão, 27 fev. 2018. Diário de Justiça do Estado de São Paulo - Judicial - $2^{\mathrm{a}}$ Instância. p. 2251.

29. Erens GA, Walter B, Crowler M. Total hip arthroplasty [Internet]. Waltham, MA: UpToDate Inc.; 2019 [Acesso em 2019 nov. 2]. Disponível em: https://www.uptodate. com

30. Gomes LSM. Cirurgia preservadora do quadril adulto. $1^{\text {a }}$ ed. São Paulo: Atheneu; 2015.

31. Pivec R, Johnson AJ, Mears SC, Mont MA. Hip arthroplasty. The Lancet. 2012;380(9855):1768-77. DOI: https://doi.org/10.1016/S0140-6736(12)60607-2

32. Berry DJ, Maloney WJ. Master techniques in orthopaedic surgery: the hip. $3^{\text {rd }}$ ed. Riverwoods: Lippincott Williams \& Wilkins; 2015.

33. Pai M, Douketis JD. Prevention of venous thromboembolism in adult orthopedic surgical patients [Internet]. Waltham, MA: UpToDate Inc.; 2019 [Acesso em 2019 nov. 2]. Disponível em: https://www.uptodate. com

34. Bhandari M, Swiontkowski M. Management of acute hip fracture. N Engl J Med. 2017;377(21):2053-62. DOI: https://doi.org/10.1056/NEJMcp1611090

35. Ceará. Tribunal de Justiça do Ceará. Vara da Fazenda Pública da Comarca de Fortaleza - $1^{\text {a }}$ Vara da Fazenda Pública. Processo 0155314-64.2018.8.06.0001. Raimundo Kelson Ferreira da Silva e Instituto Dr. Jose Frota - IJF. Juiz: Hortênsio Augusto Pires Nogueira. Decisão, 11 jan. 2019. Diário de Justiça do Estado do Ceará - Judiciário. p. 409.

36. Brasil. Agência Nacional de Saúde Suplementar. Resolução Normativa $\mathrm{n}^{\circ} 387$, de 28 de outubro de 2015. Atualiza o Rol de Procedimentos e Eventos em Saúde, que constitui a referência básica para cobertura assistencial mínima nos planos privados de assistência à saúde, contratados a partir de $1^{\circ}$ de janeiro de 1999; fixa as diretrizes de atenção à saúde; revoga as Resoluções Normativas - RN n ${ }^{\circ} 338$, de 21 de outubro de 2013, RN $\mathrm{n}^{\mathrm{o}} 349$, de 9 de maio de 2014; e dá outras providências [Internet]. [Acesso em 2019 nov. 2]. Disponível em: http://www.ans.gov.br/component/legislacao/?view=leg islacao\&task $=$ TextoLei\& format $=$ raw\&id $=$ MzExMA==

37. São Paulo. Tribunal de Justiça de São Paulo. Foro Regional XI - Pinheiros - $3^{\text {a }}$ Vara Cível - $9^{\mathrm{a}}$ Câmara de Direito Privado. Processo 2131909-78.2016.8.26.0000. Gabriela da Gama Porto Silva e Sul América Companhia de Seguro Saúde. Relator: Des. José Aparício Coelho Prado Neto. Acórdão, 25 out. 2016. Diário de Justiça do Estado de São Paulo - Judicial - $2^{\mathrm{a}}$ Instância. p. 1753.

38. Pernambuco. Tribunal de Justiça do Estado de Pernambuco. Súmula $\mathrm{n}^{\mathrm{o}}$ 54. É abusiva a negativa de cobertura de próteses e órteses, vinculadas ou consequentes de procedimento cirúrgico, ainda que de cobertura expressamente excluída ou limitada, no contrato de assistência à saúde [Internet]. Departamento 
Fabricio AS et al. Jurisprudência do Tribunal de São Paulo em ações de responsabilidade civil por erro médico.

de Pesquisa Judiciária 219 p. 7. 2008 dez. 18 [Acesso em 2019 nov. 2]. Disponível em: https://www.tjpe.jus. br/documents/10180/0/-/08b9a5ff-0232-469a-bd24d621219abf08

39. Pará. Tribunal de Justiça do Estado do Pará. Súmula $\mathrm{n}^{\mathrm{o}} 30$. Ainda que o contrato seja firmado anteriormente à Lei $n^{\circ} 9.656 / 1998$, é abusiva a negativa de cobertura de próteses, órteses e materiais especiais diretamente ligados ao procedimento cirúrgico [Internet]. Dário da Justiça Eletrônico. 2017 set. 20 [Acesso em 2019 nov. 2]. Disponível em: http://www.tjpa.jus.br//CMSPortal/Visua lizarArquivo?idArquivo $=583031$

40. Rio de Janeiro. Superior Tribunal de Justiça do Estado do Rio de Janeiro. Súmula $\mathrm{n}^{\circ} 112$. É nula, por abusiva, a cláusula que exclui de cobertura a órtese que integre, necessariamente, cirurgia ou procedimento coberto por plano ou seguro de saúde, tais como "stent" e marcapasso [Internet]. Diário Oficial do Estado do Rio de Janeiro. 2006 out. 24 [Acesso em 2019 nov. 2]. Disponível em: http://www4.tjrj.jus.br/biblioteca/index.asp?codigo sophia $=150810$

41. Rio de Janeiro. Superior Tribunal de Justiça do Estado do Rio de Janeiro. Súmula ${ }^{\circ} 211$. Havendo divergência entre o seguro saúde contratado e o profissional responsável pelo procedimento cirúrgico, quanto à técnica e ao material a serem empregados, a escolha cabe ao médico incumbido de sua realização [Internet]. Diário da Justiça Eletrônico do Estado do Rio de Janeiro. 2011 mai. 9 [Acesso em 2019 nov. 2]. Disponível em: http://www4. tjrj.jus.br/biblioteca/index.asp?codigo_sophia $=150787$

42. Rio de Janeiro. Superior Tribunal de Justiça do Estado do Rio de Janeiro. Súmula $n^{\circ} 340$. Ainda que admitida a possibilidade de o contrato de plano de saúde conter cláusulas limitativas dos direitos do consumidor, revelase abusiva a que exclui o custeio dos meios e materiais necessários ao melhor desempenho do tratamento da doença coberta pelo plano [Internet]. Diário da Justiça Eletrônico do Estado do Rio de Janeiro. 2015 jun. 29 [Acesso em 2019 nov. 2]. Disponível em: http://www4. tjrj.jus.br/biblioteca/index.asp?codigo_sophia $=188063$

43. Brasil. Conselho Federal de Medicina (CFM). Resolução CFM n ${ }^{\circ}$ 2.217, de 27 de setembro de 2018. Aprova o Código de Ética Médica. Diário Oficial da União. 2018 nov. $1^{\text {o }}$; Seção I. p. 179.

44. São Paulo. Assembleia Legislativa do Estado de São Paulo. Lei $\mathrm{n}^{\circ}$ 10.241, de 17 de março de 1999. Dispõe sobre os direitos dos usuários dos serviços e das ações de saúde no Estado [Internet]. São Paulo, SP; 1999. [Acesso em 2019 nov. 2]. Disponível em: https://www.al.sp.gov. br/repositorio/legislacao/lei/1999/lei-10241-17.03.1999. html

45. São Paulo. Assembleia Legislativa do Estado de São Paulo. Lei Complementar no 791, de 09 de março de 1995. Estabelece o Código de Saúde no Estado [Internet]. São Paulo, SP; 1995. [Acesso em 2019 nov. 2]. Disponível em: https://www.al.sp.gov.br/repositorio/legislacao/lei. complementar/1995/lei.complementar-791-09.03.1995. html

46. Vieira da Motta M, Mena H, Piacsek G. Urgência e Emergência: os conceitos frente às normas administrativas e legais e suas implicações na clínica médica. Saúde, Ética \& Justiça. 2017;22(2):81-94. DOI: https://doi. org/10.11606/issn.2317-2770.v22i2p81-94

47. São Paulo. Tribunal de Justiça de São Paulo. Foro Regional V - São Miguel Paulista da Comarca de São Paulo, SP - $5^{\text {a }}$ Câmara Direito Privado. Processo 101799283.2016.8.26.0005. Célia Cabral Pinto e Unimed Seguros Saúde S/A. Relator: Des. Fábio Podestá. Acórdão, 11 out. 17. Diário de Justiça do Estado de São Paulo - Judicial -

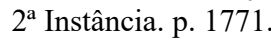

48. Queiroz R, Grinbaum RS, Galvão LL, Tavares FG, Bergsten-Mendes G. Antibiotic prophylaxis in orthopedic surgeries: the results of an implemented protocol. Braz J Infect Dis. 2005;9(4):283-7. DOI: https:// doi.org/10.1590/S1413-86702005000400003

49. Jarvis WR. Selected aspects of socioeconomic impact of nosocomial infections: morbidity, mortality, cost, and prevention. Infect Control Hosp Epidemiol. 1996;17(8):552-7. DOI: https://doi.org/10.1086/647371

50. Jones RN. Global epidemiology of antimicrobial resistance among community-acquired and nosocomial pathogens: a five-year summary from the SENTRY Antimicrobial Surveillance Program (1997-2001). Semin Respir Crit Care Med. 2003;24(1):121-34. DOI: https:// doi.org/10.1055/s-2003-37923

51. Brasil. Superior Tribunal de Justiça. REsp 138059 MG 1997/0044326-4. Civil. Responsabilidade civil. Prestação de serviços médicos. Quem se compromete a prestar assistência médica por meio de profissionais que indica, é responsável pelos serviços que estes prestam. Recurso especial não conhecido. Relator: Ministro Ari Pargendler. $3^{\text {a }}$ Turma. Julgamento, 13 mar. 2001. LEXSTJ v.146. p.104. 